Original Article

\title{
Effects of food restriction on the expression of genes related to acetaminophen-induced liver toxicity in rats
}

\author{
Yuya Tsuchiya ${ }^{1,2}$, Hiroki Sakai², Akihiro Hirata ${ }^{3}$, and Tokuma Yanai ${ }^{*}$ \\ ${ }^{1}$ Nagaragawa Research Center, API Co., Ltd., 692-3 Nagara, Gifu-shi, Gifu 502-0071, Japan \\ ${ }^{2}$ Laboratory of Veterinary Pathology, Department of Veterinary Medicine, Gifu University, 1-1 Yanagido, Gifu-shi, Gifu 501-1193, \\ Japan \\ ${ }^{3}$ Division of Animal Experiment, Life Science Research Center, Gifu University, 1-1 Yanagido, Gifu-shi, Gifu 501-1193, Japan
}

\begin{abstract}
It is well known that fasting substantially affects the metabolism of drugs and chemicals. Food restriction also affects drug kinetics, such as absorption, metabolism, and excretion, and therefore, it can potentially modulate the onset of chemical toxicity or drug-induced adverse reactions. In the present study, the expression of drug-metabolizing enzyme genes and total glutathione content in the liver, which are related to toxicity induced by overdose of the hepatotoxic drug acetaminophen ( $N$-acetyl- $p$-aminophenol; APAP), were examined in rats reared under different feeding conditions: ad libitum feeding, 16-h fasting, and food restriction (fed $70 \%$ of the average intake of ad libitum feeding for 10 days) conditions. The rats under food restriction conditions as well as fasted rats showed significantly higher expression of Cyp2el, the gene encoding the enzyme that metabolizes APAP to its toxic metabolite $N$-acetyl- $p$-benzoquinone imine (NAPQI). They also had lower levels of liver total glutathione, which detoxifies NAPQI. In contrast, the gene expression of UDP-glucuronosyltransferase 1A6 (Ugtla6), sulfotransferase 1A1 (Sult1a1), and glutathione S-transferase M1 (Gstml) was not affected by food restriction or fasting. When APAP was administered ( $800 \mathrm{mg} / \mathrm{kg})$, histopathological changes were not observed in rats fed ad libitum, while hepatocellular necrosis was observed in most of the rats treated with APAP after fasting or food restriction. Taken together, these results suggest that not only fasting but also food restriction exacerbate APAP-induced acute liver injury, probably by the induction of CYP2E1 and the reduction of liver glutathione contents, in rodents. (DOI: 10.1293/tox.2018-0009; J Toxicol Pathol 2018 31: 267-274)
\end{abstract}

Key words: acetaminophen, hepatotoxicity, food restriction, cytochrome P450 2E1, glutathione

\section{Introduction}

Recently, calorie restriction, which affects lifespan and age-related diseases, has garnered increasing interest from researchers ${ }^{1,2}$. Calorie restriction is defined as a reduction in calorie intake without malnutrition 1 . Food restriction, one of the means of calorie restriction, increases insulin sensitivity by lowering blood insulin and insulin-like growth factor 1 levels and decreases the risk of diabetes and obesity3. It also increases the gene expression of antioxidant enzymes by activating AMP-dependent kinase and sirtuins ${ }^{1,4}$, , promoting autophagy ${ }^{3}, 5$, inhibiting the transcriptional activity of nuclear factor kappa $\mathrm{B}^{6}$, and suppressing chronic inflammation in animals ${ }^{2}$. Thus, food restriction prevents age-re-

Received: 19 February 2018, Accepted: 17 May 2018

Published online in J-STAGE: 16 June 2018

*Corresponding author: T Yanai (e-mail: yanai@gifu-u.ac.jp)

(C)2018 The Japanese Society of Toxicologic Pathology

This is an open-access article distributed under the terms of the Creative Commons Attribution Non-Commercial No Derivatives (by-nc-nd) License. (CC-BY-NC-ND 4.0: https
creativecommons.org/licenses/by-nc-nd/4.0/). lated diseases, such as cancer, neurodegeneration, cardiovascular disorders, and type II diabetes ${ }^{2}$. Indeed, in rhesus macaques, food restriction (to $70 \%$ of the average intake) extended lifespan and reduced the incidence of diabetes and cardiovascular disorders 7 . Food restriction (to $60 \%$ to $70 \%$ of the average intake) also suppressed tissue damages, including renal damage caused by cisplatin ${ }^{8}$ or ischemia ${ }^{9}$, and hepatic damage induced by aflatoxin $\mathrm{B}^{10}$ or ethanol ${ }^{11}$ in mice and rats. Feeding conditions can affect chemical toxicity because chemical absorption and metabolism change based on nutritional status ${ }^{12}$. In fact, food restriction alters the gene expression and activity of P-glycoprotein, which is involved in chemical absorption in the small intestine ${ }^{13}$. These findings indicate that food restriction may change the kinetics of drug absorption, metabolism, and excretion, thereby determining the threshold and/or degree of chemical toxicity.

Acetaminophen ( $N$-acetyl- $p$-aminophenol; APAP) is one of the most extensively used analgesics and antipyretic agents worldwide. When administered orally, APAP is mostly absorbed by passive diffusion through small intestinal epithelial cells ${ }^{14-16}$, and then it is excreted in the urine after conjugation with glucuronic acid or sulfate by UDP- 
glucuronosyltransferases or sulfotransferases, respectively, in the liver. In addition, APAP is metabolized to its active metabolite $N$-acetyl-p-benzoquinone imine (NAPQI) in part by the liver metabolic enzyme CYP2E1. NAPQI is detoxified through conjugation with glutathione by glutathione S-transferases and excreted in the bile ${ }^{14,16,17}$. It is well documented that overdose of APAP causes acute liver injury and liver failure in humans ${ }^{18,19}$ and rodents ${ }^{20}$. When an overdose of APAP is ingested, large amounts of NAPQI are formed, which depletes liver glutathione and causes hepatocellular necrosis due to mitochondrial dysfunction and the peroxidation of biological macromolecules ${ }^{21-23}$. Importantly, human APAP-induced liver injury can be caused by sub-toxic doses under fasting ${ }^{24-26}$ or long-term nutrient-poor conditions ${ }^{27,28}$, indicating that poor nutrition can lower the threshold for APAP-induced hepatic toxicity. However, while it was demonstrated that fasting worsens APAP-induced liver injury in rodents ${ }^{29,30}$, there are few reports on the effect of food restriction without malnutrition on APAP-induced liver injury.

In the present study, we examined the gene expression of enzymes involved in APAP metabolism, including UDPglucuronosyltransferase 1A6 (Ugtla6), sulfotransferase 1A1 (Sult1a1), cytochrome P450 2E1 (Cyp2e1), and glutathioneS-transferase M1 (Gstm1), and the total glutathione content in the rat liver under fasting and food restriction conditions in comparison with those in the livers of rats fed ad libitum. Moreover, we compared the frequency and degree of APAPinduced toxicity under the different feeding conditions.

\section{Materials and Methods}

\section{Animals and feeding conditions}

Male Wistar/ST rats (6-7 weeks old) were purchased from Japan SLC (Shizuoka, Japan), fed a normal diet (CE-2; CREA Japan, Tokyo, Japan), and maintained under standard conditions at $23 \pm 1{ }^{\circ} \mathrm{C}$ with $55 \pm 10 \%$ humidity and a controlled light/dark schedule (light from 08:00 to 20:00). The animals were adapted to the rearing environment for approximately 1 week and then reared under 3 different conditions: 1) ad libitum feeding (ALF); 2) 16-h fasting (Fasting), in which animals were not fed from 17:00 to 09:00 on the following day; and 3) restricted feeding (RF), in which the animals were given $14 \mathrm{~g}$ of chow, which constituted $70 \%$ of the average daily food intake (approximately $20 \mathrm{~g}$ ), at 17:00 every day for 10 days. The feed dosage in the RF group was determined in accordance with a previous report ${ }^{31}$. All animals were individually housed and had free access to tap water. This study was performed in accordance with the laboratory animal welfare regulations of our company based on the Standards Relating to the Care and Management of Laboratory Animals and Relief of Pain (Notice No. 88 of the Ministry of Environment dated April 28, 2006), and the protocol of the animal study was approved by the Animal Ethics Committee of API (protocol \# 42-002).
Measurement of the expression of drug-metabolizing enzyme genes and liver glutathione content

The animals were divided into ALF, Fasting, and RF groups and were sacrificed by exsanguination under isoflurane (Wako Pure Chemical Industries, Osaka, Japan) anesthesia (ALF and Fasting groups, 09:00, n=5 each; RF group, 09:00 or 16:00, $\mathrm{n}=5$ at each time point). The livers were immediately collected, weighed, minced, and frozen in liquid nitrogen. The liver samples were stored at $-80^{\circ} \mathrm{C}$ until analysisfor mRNA levels of APAP-related metabolic enzymes and glutathione content. For gene expression analysis, liver tissue (approximately $50 \mathrm{mg}$ ) was homogenized in $1 \mathrm{~mL}$ of ISOGEN ${ }^{\circledR}$ II (Nippon Gene, Tokyo, Japan) using a Polytron ${ }^{\circledR}$ PT1300D (Kinematica, Lucerne, Switzerland) and then sterilized, and ultrapure water was added to the homogenates. The homogenates were centrifuged at $12,000 \times g$ for $15 \mathrm{~min}$ at $4^{\circ} \mathrm{C}$, and the supernatants were collected and analyzed. Total RNA was extracted and purified using 4-bromoanisole (Wako Pure Chemical Industries) and $8 \mathrm{mM}$ lithium chloride solution (Nacalai Tesque, Kyoto, Japan). cDNA was synthesized from the total RNA with SuperScript ${ }^{\mathrm{TM}}$ III First-Strand Synthesis SuperMix for qRT-PCR (Thermo Fisher Scientific, Waltham, MA, USA) and used for quantitative polymerase chain reaction (PCR) analyses. Quantitative PCR was conducted on an Applied Biosystems 7300 Real-Time PCR System (Thermo Fisher Scientific), using 40 cycles at $95^{\circ} \mathrm{C}$ for $15 \mathrm{~s}$ and $60^{\circ} \mathrm{C}$ for $1 \mathrm{~min}$. The enzyme involved in APAP metabolism was selected according to previous reports ${ }^{16}, 17,26-28$ and primers for Ugtla6, Sult1al, Cyp2el, Gstm1, and glyceraldehyde3-phosphate dehydrogenase (Gapdh) were designed using Primer-BLAST (Table 1; https://www.ncbi.nlm.nih.gov/ tools/primer-blast/) based on the sequences obtained from the NCBI Reference Sequence Database (https://www.ncbi. nlm.nih.gov/refseq/). The mRNA level of each gene was normalized to that of Gapdh.

For measurement of liver glutathione content, liver tissue (approximately $100 \mathrm{mg}$ ) was homogenized in $1 \mathrm{~mL}$ of 5\% (w/v) 5-sulfosalicylic acid (Nacalai Tesque) solution using a Polytron ${ }^{\circledR}$ PT1300D. The homogenates were centrifuged at $8,000 \times g$ for $10 \mathrm{~min}$ at $4^{\circ} \mathrm{C}$, and the supernatants were collected to measure the glutathione contents. Total glutathione contents were measured with a GSSG/GSH Quantification Kit (Dojindo Laboratories, Kumamoto, Japan) and presented as moles of glutathione per whole liver.

\section{Assessment of APAP-induced liver injury}

APAP (Nacalai Tesque) was dissolved in $0.5 \%(\mathrm{w} / \mathrm{v})$ methylcellulose (Shin-Etsu Chemical, Tokyo, Japan) solution, which was administered to the animals by oral gavage at $800 \mathrm{mg} / \mathrm{kg}$, which is equivalent to twice the daily maximum dose in humans. The animals were divided into ALF $(n=3)$, Fasting $(n=5)$, and RF $(n=5)$ groups according to the feeding conditions before APAP administration. APAP was orally administered to the ALF and Fasting groups at 09:00 and to the RF group at 16:00. After APAP administration, animals in the ALF and Fasting groups were fed freely from 
Table 1. PCR Primers

\begin{tabular}{|c|c|c|c|c|}
\hline Gene name & Accession no. & $\mathrm{F}$ or $\mathrm{R}$ & Sequence & Product size $(b p)$ \\
\hline Ugtla6 & & $\mathrm{R}$ & 5'-CCATCGCTTTCTTCTCTGGAATC-3' & \\
\hline Sultla1 & & $\mathrm{R}$ & 5'-AGACAACCACATCCTTTGCATTT-3' & \\
\hline \multirow[t]{2}{*}{ Cyp2e1 } & NM_031543.1 & $\mathrm{F}$ & 5'-CTGAGACCACCAGCACAACT-3' & 102 \\
\hline & & $\mathrm{R}$ & 5'-GCCCAATAACCCTGTCAATTTCT-3' & \\
\hline Gstm1 & & $\mathrm{R}$ & 5'-CACTGGCTTCTGTCATAGTCG-3' & \\
\hline \multirow[t]{2}{*}{ Gapdh } & NM_017008.4 & $\mathrm{F}$ & 5'-GACATGCCGCCTGGAGAA-3' & 102 \\
\hline & & $\mathrm{R}$ & 5'-AGCCCAGGATGCCCTTTAGT-3' & \\
\hline
\end{tabular}

F: forward primer, R: reverse primer.

10:00 and then euthanized after overnight fasting, and those in the RF group were given $14 \mathrm{~g}$ diet at 17:00 and euthanized after daytime fasting. Twenty-four hours after the administration of APAP, blood samples were drawn into tubes containing a serum-separating agent from an abdominal vein under isoflurane anesthesia (Terumo, Tokyo, Japan). Liver samples were immediately collected, weighed, fixed in 10\% neutral-buffered formalin (Wako Pure Chemical Industries), and embedded in paraffin. Paraffin-embedded tissue sections were stained with hematoxylin and eosin (Wako Pure Chemical Industries) for histopathological analysis by light microscopy. Blood samples were centrifuged at 2,000 $\times g$ for $15 \mathrm{~min}$ at $4^{\circ} \mathrm{C}$, and the serum was collected for the measurement of alanine transaminase (ALT) and aspartate transaminase (AST) levels by FUJI DRI-CHEM (Fujifilm, Tokyo, Japan).

\section{Statistical analysis}

Statistical analyses were performed using EkuseruToukei 2012 (Social Survey Research Information, Tokyo, Japan). After examining the homogeneity of variance among the experimental groups with Bartlett's test, Dunnett's or Steel's multiple comparison tests were used for parametric or nonparametric analyses, respectively, to compare mRNA levels, liver glutathione contents, and ALT and AST levels. In the RF group, Student's $t$-test was used for comparison of the liver glutathione contents between 2 time points. Differences were considered significant when the $p$-value was less than $0.05(p<0.05)$.

\section{Results}

\section{Clinical signs, body weight, and food consumption}

Abnormal clinical symptoms were not observed in any of the groups. The mean body weight of the RF group was approximately $83 \%$ of that of the ALF group; no decrease in body weight gain was observed during the period of food restriction (data not shown). The RF animals consumed their full allotment of chow ( $14 \mathrm{~g} /$ day $)$ throughout the experimental period.
Effects of food restriction on the gene expression of drug-metabolizing enzymes and the total glutathione content in the liver

As shown in Fig. 1C, the mRNA levels of Cyp2el were significantly higher in the Fasting and RF groups than in the ALF group ( $p<0.01$, respectively). The mRNA levels of Ugtla6, Sult1al, and Gstm1 were similar among the groups (Fig. 1A, B, and D).

The total glutathione contents in the liver significantly decreased after the 16 -h fast $(p<0.01)$. The values of the RF group sacrificed at 09:00 decreased to $86 \%$ of the value of the ALF group, although the difference was not significant (Fig. 2). Furthermore, during $8 \mathrm{~h}$ in the light phase (09:00-17:00), there was a highly significant reduction in the liver glutathione content in the rats reared under food restriction $(p<0.01)$, and the RF group sacrificed at 16:00 had significantly lower glutathione contents than the ALF group $(p<0.01)$

\section{APAP-induced liver injury in rats under different feeding conditions}

Histological changes were not observed in the animals administered APAP under the ALF condition (Fig. 3A). On the other hand, centrilobular hepatocellular necrosis with inflammatory cell infiltration was observed in 2 out of the 5 animals in the Fasting group (Fig. 3B), and single-cell hepatocellular necrosis with inflammatory cell infiltration around central veins was observed in 2 out of the remaining 3 animals. Consistently, the serum ALT and AST levels were approximately 1.5 -fold higher and more than 3 -fold higher, respectively, in the 2 animals with centrilobular hepatocellular necrosis than in the animals without hepatocellular necrosis (Table 2). The serum AST levels were approximately 1.4-fold higher in the 2 animals with singlecell hepatocellular necrosis than in the animals without hepatocellular necrosis (Table 2). In the RF group, single-cell hepatocellular necrosis with inflammatory cell infiltration around the central veins was observed in 3 out of the 5 animals (Fig. 3C and D). The serum AST, but not ALT, levels of in the animals with single-cell hepatocellular necrosis were very slightly higher than in the animals without hepatocellular necrosis (Table 2). Significant differences in the serum ALT and AST levels among the groups were not observed. 
A

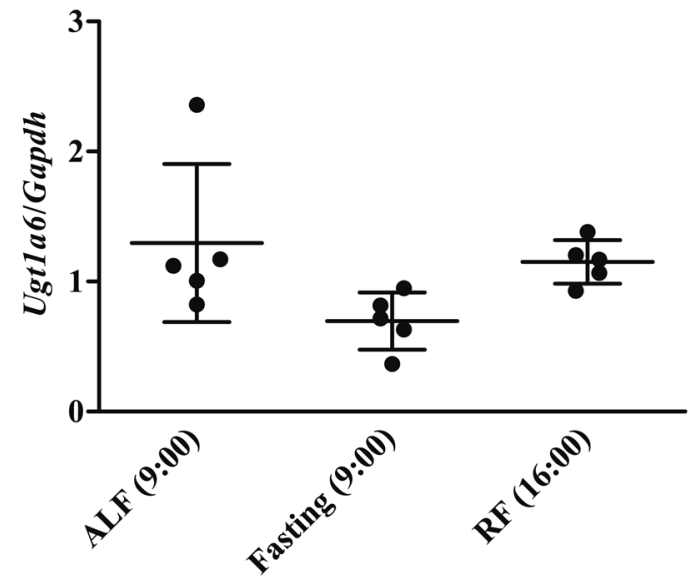

C $* *$

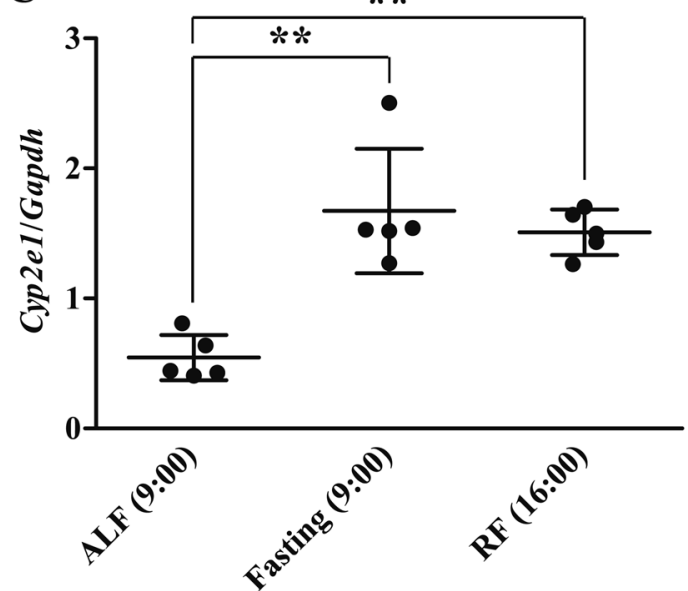

B

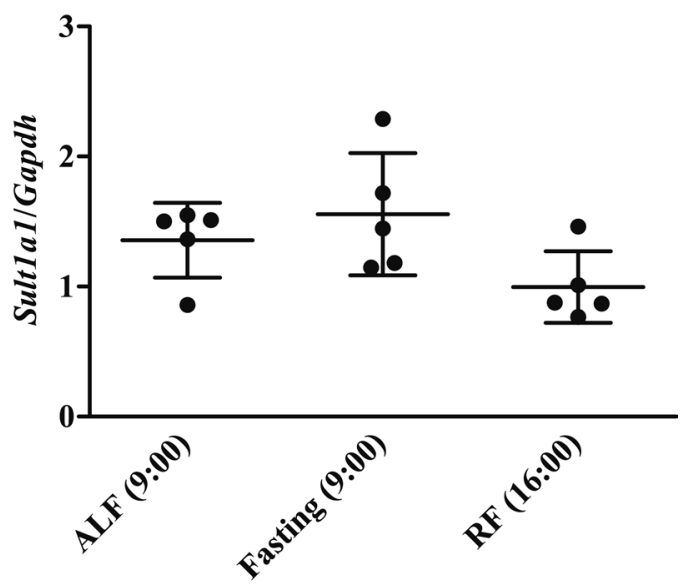

D

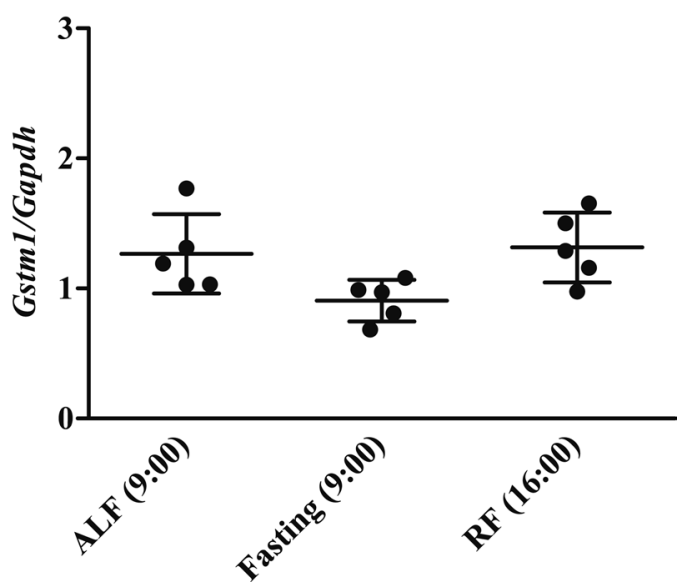

Fig. 1. mRNA levels of the drug-metabolizing enzymes UDP-glucuronosyltransferase 1A6 (Ugt1A6), sulfotransferase 1A1 (Sult1A1), cytochrome P450 2E1 (Cyp2el), and glutathione S-transferase M1 (Gstml) under the different conditions of feeding. The gene expression levels are normalized to Gapdh expression. The solid circles represent individual values, and the horizontal bars indicate the mean (middle) and standard deviation (upper and lower) values for each group. The sampling times are shown in parentheses. ALF, ad libitumfed group; Fasting, 16-h-fasted group; and RF, food-restricted ( $70 \%$ of the average intake) group. ${ }^{* *} p<0.01$ versus the ALF (09:00) group, assessed by Steel's test.

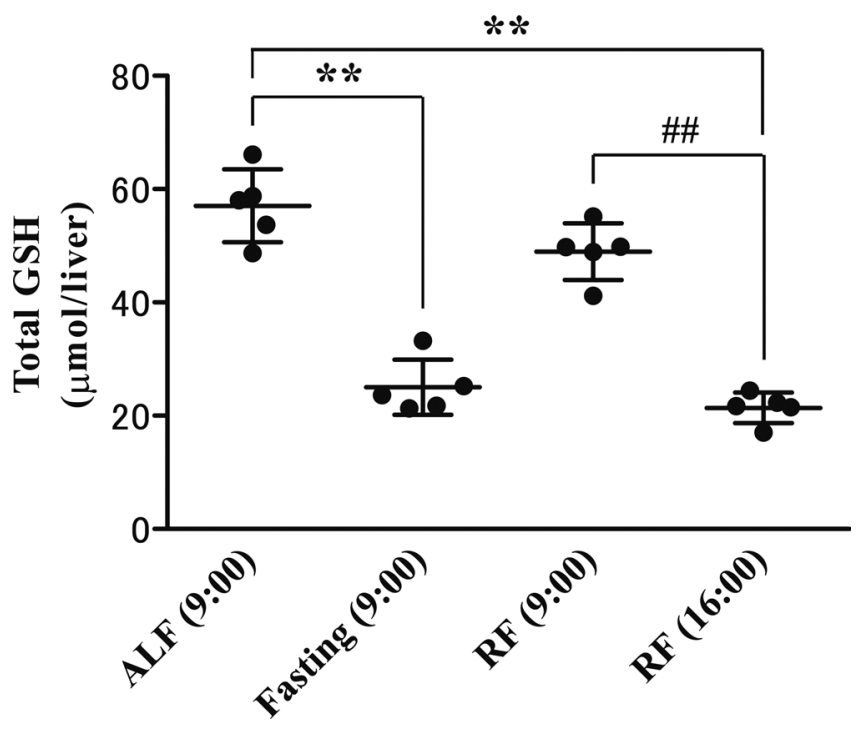

Fig. 2. Total liver glutathione content under the different feeding conditions. The solid circles represent individual values, and the horizontal bars indicate the mean (middle) and standard deviation (upper and lower) for each group. The sampling times are shown in parentheses. ALF, ad libitum-fed group; Fasting, 16-h-fasted group; RF, food-restricted ( $70 \%$ of the average intake) group; and GSH, glutathione. $* * p<0.01$ versus the ALF (09:00) group, assessed by Dunnett's test. \#\# $p<0.01$ versus the RF (09:00) group, assessed by Student's $t$-test.

Fig. 2. 


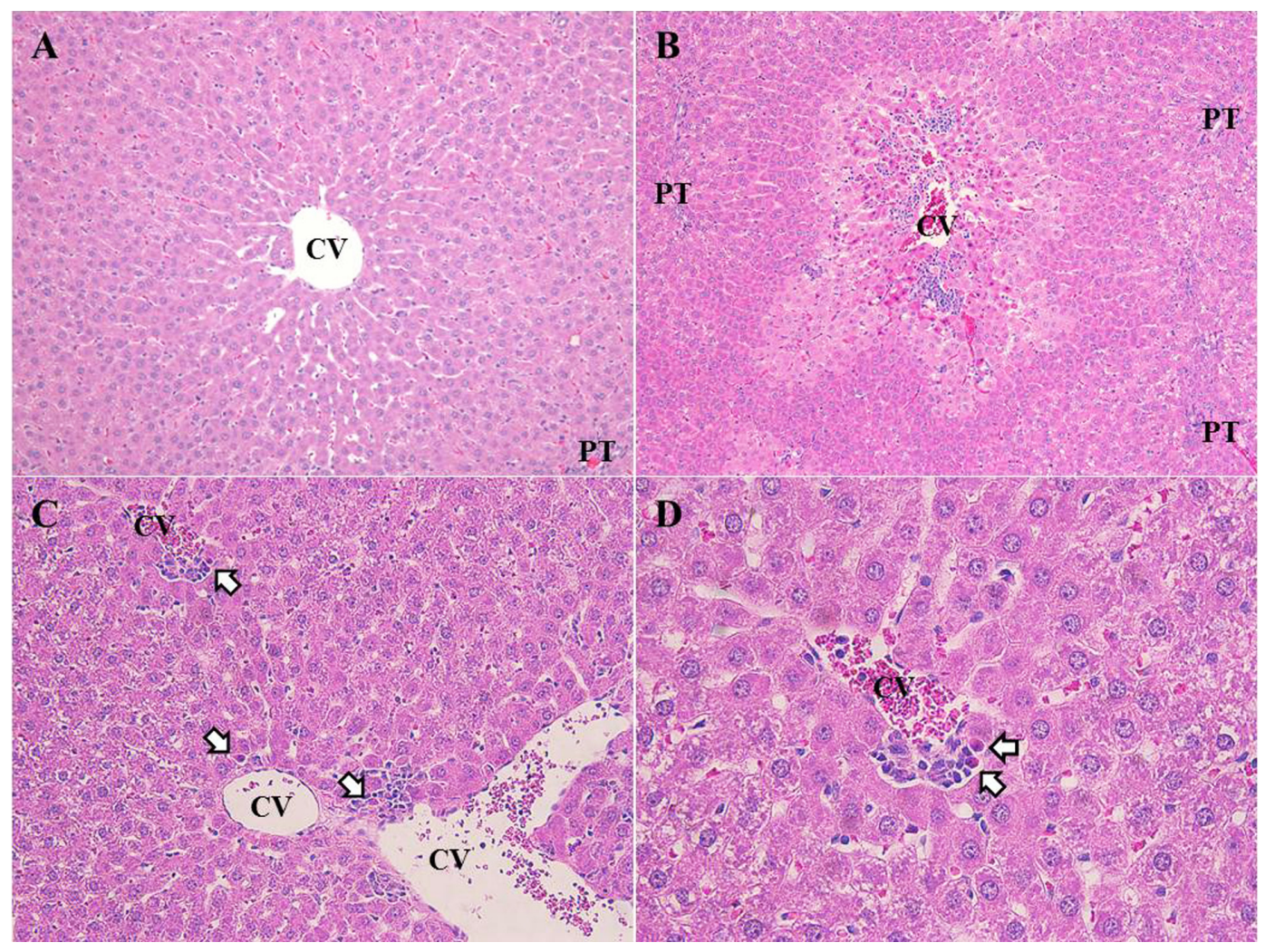

Fig. 3. Representative images of the histopathological changes in the liver after oral administration of APAP ( $800 \mathrm{mg} / \mathrm{kg})$ under the different feeding conditions. The (A) ad libitum-fed rats were euthanized at 09:00, and no abnormality was observed. (B) The 16-h-fasted rats were euthanized at 09:00, and centrilobular hepatocellular necrosis with inflammatory cell infiltration was observed. (C and D) The foodrestricted ( $70 \%$ of the average intake) rats were euthanized at 16:00, and single hepatocellular necrosis with inflammatory cell infiltration was observed. The arrows indicate single hepatocellular necrosis. CV, central vein; PT, portal triad. Tissue specimens were stained with hematoxylin and eosin. Magnification: A and B, 100×; C, 200×; and D, 400×).

Table 2. The Degree of Hepatocellular Necrosis and the Serum ALT And AST Levels after Oral Administration of APAP $(800 \mathrm{Mg} / \mathrm{Kg})$ under the Different Feeding Conditions

\begin{tabular}{|c|c|c|c|c|c|}
\hline \multirow{2}{*}{ Feeding condition } & \multirow{2}{*}{$\begin{array}{l}\text { Time of APAP } \\
\text { administration }\end{array}$} & \multicolumn{2}{|c|}{ Hepatocellular necrosis } & \multirow{2}{*}{$\operatorname{ALT}(\mathrm{U} / \mathrm{L})$} & \multirow{2}{*}{$\operatorname{AST}(\mathrm{U} / \mathrm{L})$} \\
\hline & & Centrilobular & Single cell & & \\
\hline \multirow[t]{3}{*}{ Ad libitum feeding } & 9:00 & - & - & 41 & 84 \\
\hline & & - & - & 53 & 77 \\
\hline & & - & - & 59 & 93 \\
\hline \multirow[t]{5}{*}{$16-\mathrm{h}$ fasting } & 9:00 & + & - & 92 & 283 \\
\hline & & + & - & 82 & 380 \\
\hline & & - & + & 49 & 115 \\
\hline & & - & + & 53 & 125 \\
\hline & & - & - & 40 & 79 \\
\hline \multirow[t]{5}{*}{ Restricted feeding } & $16: 00$ & - & + & 51 & 100 \\
\hline & & - & - & 37 & 61 \\
\hline & & - & + & 48 & 83 \\
\hline & & - & + & 59 & 102 \\
\hline & & - & - & 39 & 59 \\
\hline
\end{tabular}

+: observed, -: not observed.

\section{Discussion}

In the present study, we found that the expression of Cyp2el was higher under the fasting condition than under the ad libitum feeding condition, consistent with previous reports indicating that CYP2E1 expression is enhanced by fasting 27, 32-34. Importantly, Cyp2el expression was upregulated to a similar level under food restriction. When the 
supply of carbohydrates is limited, citric acid is synthesized from acetyl-CoA produced by $\beta$-oxidation of fatty acids in the liver, and citric acid generates bioenergy via the tricarboxylic acid cycle 35 . Ketone bodies, such as acetoacetic acid, $\beta$-hydroxy (lactic) acid, and acetone, which are also synthesized from acetyl-CoA in the liver, circulate in the blood and are used as bioenergy sources ${ }^{35}$. Acetone potently induces CYP2E1 activity ${ }^{28,32}$ and there is a positive correlation between the blood concentration of acetone and hepatic CYP2E1 activity ${ }^{34}$. In previous studies, the blood concentration of ketone bodies increased in the setting of food restriction $\left(80 \%\right.$ of the average intake) for 3 weeks ${ }^{36}$, while a single day of restricted feeding (75\% of average intake) did not change CYP2E1 activity ${ }^{37}$. It is possible that ketone body metabolites increase due to energy insufficiency under fasting and food restriction ( $70 \%$ of the average intake) for 10 days, leading to the induction of CYP2E1. In the present study, Cyp2el mRNA expression under food restriction was examined at 16:00 in order to render the effect of food restriction more obvious, while the rats were euthanized at 9:00 under ad libitum feeding and fasting conditions. Although CYP2E1 shows a substantial circadian variation in rats, it has been shown that the extent of daily fluctuation of CYP2E1 activity is much smaller than the elevation induced by fasting ${ }^{34}$. Therefore, the upregulation of the Cyp2el gene was thought to be due to the food restriction.

We also found that liver glutathione content decreased after $16 \mathrm{~h}$ of fasting and at 16:00 under food restriction for 10 days. Glutathione plays an important role in animals for the maintenance of a balanced cellular oxidation-reduction status; it is conjugated to and excreted with highly reactive chemicals. Glutathione is composed of cysteine, glutamic acid, and glycine. The stock of cysteine in the body is small, and its biosynthesis requires essential amino acids, such as methionine and serine ${ }^{38,39}$; the amount of glutathione is thought to decrease upon fasting due to a reduced supply of amino acids from the diet. The liver glutathione content falls to $75 \%$ of that in ad libitum-fed rats in rats fed a cysteine-deficient diet for 8 days ${ }^{38}$. Interestingly, the liver glutathione content in 24-h-fasted rats was approximately $40 \%$ of that in non-fasted rats and was maintained, in spite of continuous fasting for $48 \mathrm{~h}$ or $72 \mathrm{~h}^{39}$, suggesting that animals maintain their liver glutathione content under fasting conditions to protect against reactive oxygen species or highly reactive chemicals. The rats in the RF group, which received a uniformly low supply of cysteine, methionine, and serine, may have had a lower level of glutathione biosynthesis than the ad libitum-fed rats. In a previous report, food restriction ( $75 \%$ of average intake) for 1 day did not change the glutathione content of the rat liver ${ }^{37}$; however, the 10-day food restriction tended to lower the liver glutathione content in the present study. The discrepancy might be due to the difference in the duration of food restriction; the supply of cysteine from the diet may have been continuously lower during our 10-day restriction period than in the 1-day restriction period. Cysteine is preferentially used for protein synthesis to maintain vital functions ${ }^{40}$, and a deficiency ap- pears to limit the amount of liver glutathione available for drug metabolism. Previous studies reported that, because rats mainly feed in the dark phase, their liver glutathione content is highest at the beginning of the light phase, decreases with time, and finally settles at approximately $70 \%$ of the peak value at the end of the light phase ${ }^{34,41}$. In this study, we found that the liver glutathione content at the end of the light phase (at 16:00) was $44 \%$ of that observed at the beginning of the light phase (at 09:00) in the food-restricted rats, indicating that glutathione content could fluctuate under the food restriction condition. This result also indicates that daily variations in liver glutathione content might be larger under food restriction than under ad libitum feeding.

We also evaluated the development of APAP-induced liver injury under various feeding conditions. We selected a dose of $800 \mathrm{mg} / \mathrm{kg}$, which is non-toxic to the liver under ad libitum feeding. Of note, hepatocellular necrosis was observed under food restriction as well as under fasting condition, while no change was observed under ad libitum feeding, as expected. Interestingly, although the changes in Cyp2el expression and liver glutathione content were nearly equivalent under food restriction and fasting, the degree of APAP-induced hepatocellular necrosis was lower in the food-restricted rats than in the fasted rats, which suggests that other factors are also implicated in APAP toxicity. As reported in previous studies ${ }^{42-45}$, the activity of other antioxidant enzymes, such as superoxide dismutase, catalase, and glutathione peroxidase, may be increased under the fasting or food-restricted conditions. In addition, we observed individual differences in the development of hepatocellular necrosis with the elevation of serum ALT and AST levels in the fasted and food-restricted rats. The precise causes of the individual differences in hepatotoxicity caused by APAP are unclear, but these differences can likely be attributed in part to differences in enzyme activities related to APAP metabolism, antioxidant defense, and detoxification capacity.

In conclusion, the present study indicated that higher expression of the APAP-metabolizing enzyme CYP2E1 and lower liver glutathione content can be attributed to the exacerbation of APAP-induced acute liver injury in rodents, not only under fasting but also food-restricted conditions.

Disclosure of Potential Conflicts of Interest: There are no conflicts of interest to declare.

Acknowledgment: We are grateful to the staff of the Nagaragawa Research Center, API (Gifu, Japan), for their practical advice and support. We would like to thank Editage (www.editage.jp) for English language editing.

\section{References}

1. López-Lluch G, and Navas P. Calorie restriction as an intervention in ageing. J Physiol. 594: 2043-2060. 2016. [Medline] [CrossRef]

2. Speakman JR, and Mitchell SE. Caloric restriction. Mol Aspects Med. 32: 159-221. 2011. [Medline] [CrossRef] 
3. Fok WC, Zhang Y, Salmon AB, Bhattacharya A, Gunda R, Jones D, Ward W, Fisher K, Richardson A, and Pérez VI. Short-term treatment with rapamycin and dietary restriction have overlapping and distinctive effects in young mice. J Gerontol A Biol Sci Med Sci. 68: 108-116. 2013. [Medline] [CrossRef]

4. Storz P. Forkhead homeobox type O transcription factors in the responses to oxidative stress. Antioxid Redox Signal. 14: 593-605. 2011. [Medline] [CrossRef]

5. Lee IH, Cao L, Mostoslavsky R, Lombard DB, Liu J, Bruns NE, Tsokos M, Alt FW, and Finkel T. A role for the NADdependent deacetylase Sirtl in the regulation of autophagy. Proc Natl Acad Sci USA. 105: 3374-3379. 2008. [Medline] [CrossRef]

6. Salminen A, Kauppinen A, Suuronen T, and Kaarniranta K. SIRT1 longevity factor suppresses NF-kappaB -driven immune responses: regulation of aging via NF-kappaB acetylation? BioEssays. 30: 939-942. 2008. [Medline] [CrossRef]

7. Colman RJ, Anderson RM, Johnson SC, Kastman EK, Kosmatka KJ, Beasley TM, Allison DB, Cruzen C, Simmons HA, Kemnitz JW, and Weindruch R. Caloric restriction delays disease onset and mortality in rhesus monkeys. Science. 325: 201-204. 2009. [Medline] [CrossRef]

8. Ning YC, Cai GY, Zhuo L, Gao JJ, Dong D, Cui S, Feng Z, Shi SZ, Bai XY, Sun XF, and Chen XM. Short-term calorie restriction protects against renal senescence of aged rats by increasing autophagic activity and reducing oxidative damage. Mech Ageing Dev. 134: 570-579. 2013. [Medline] [CrossRef]

9. Mitchell JR, Verweij M, Brand K, van de Ven M, Goemaere N, van den Engel S, Chu T, Forrer F, Müller C, de Jong M, van IJcken W, IJzermans JN, Hoeijmakers JH, and de Bruin RW. Short-term dietary restriction and fasting precondition against ischemia reperfusion injury in mice. Aging Cell. 9: 40-53. 2010. [Medline] [CrossRef]

10. Chou MW, Lu MH, Pegram RA, Gao P, Cao S, Kong J, and Hart RW. Effect of caloric restriction on aflatoxin B1induced DNA synthesis, AFB1-DNA binding and cell proliferation in Fischer 344 rats. Mech Ageing Dev. 70: 23-33. 1993. [Medline] [CrossRef]

11. Mladenović D, Ninković M, Aleksić V, Šljivančanin T, Vučević D, Todorović V, Stanković M, Stanojlović O, and Radosavljević T. The effect of calorie restriction on acute ethanol-induced oxidative and nitrosative liver injury in rats. Environ Toxicol Pharmacol. 36: 296-302. 2013. [Medline] [CrossRef]

12. Harris RZ, Jang GR, and Tsunoda S. Dietary effects on drug metabolism and transport. Clin Pharmacokinet. 42: 1071-1088. 2003. [Medline] [CrossRef]

13. Renaud HJ, Klaassen CD, and Csanaky IL. Calorie Restriction Increases P-Glycoprotein and Decreases Intestinal Absorption of Digoxin in Mice. Drug Metab Dispos. 44: 366-369. 2016. [Medline] [CrossRef]

14. Sabaté M, Ibáñez L, Pérez E, Vidal X, Buti M, Xiol X, Mas A, Guarner C, Forné M, Solà R, Castellote J, Rigau J, and Laporte JR. Paracetamol in therapeutic dosages and acute liver injury: causality assessment in a prospective case series. BMC Gastroenterol. 11: 80. 2011. [Medline] [CrossRef]

15. Cummings AJ, King ML, and Martin BK. A kinetic study of drug elimination: the excretion of paracetamol and its metabolites in man. Br J Pharmacol Chemother. 29: 150157. 1967. [Medline] [CrossRef]

16. Albert KS, Sedman AJ, and Wagner JG. Pharmacokinetics of orally administered acetaminophen in man. J Pharmacokinet Biopharm. 2: 381-393. 1974. [Medline] [CrossRef]

17. Clements JA, Critchley JA, and Prescott LF. The role of sulphate conjugation in the metabolism and disposition of oral and intravenous paracetamol in man. Br J Clin Pharmacol. 18: 481-485. 1984. [Medline] [CrossRef]

18. Lee WM, Squires RH Jr, Nyberg SL, Doo E, and Hoofnagle JH. Acute liver failure: Summary of a workshop. Hepatology. 47: 1401-1415. 2008. [Medline] [CrossRef]

19. Hodgman MJ, and Garrard AR. A review of acetaminophen poisoning. Crit Care Clin. 28: 499-516. 2012. [Medline] [CrossRef]

20. Jaeschke H, Williams CD, McGill MR, Xie Y, and Ramachandran A. Models of drug-induced liver injury for evaluation of phytotherapeutics and other natural products. Food Chem Toxicol. 55: 279-289. 2013. [Medline] [CrossRef]

21. Jaeschke H, and Bajt ML. Intracellular signaling mechanisms of acetaminophen-induced liver cell death. Toxicol Sci. 89: 31-41. 2006. [Medline] [CrossRef]

22. Jaeschke H, McGill MR, Williams CD, and Ramachandran A. Current issues with acetaminophen hepatotoxicity-a clinically relevant model to test the efficacy of natural products. Life Sci. 88: 737-745. 2011. [Medline] [CrossRef]

23. Bantel H, and Schulze-Osthoff K. Mechanisms of cell death in acute liver failure. Front Physiol. 3: 79. 2012. [Medline] [CrossRef]

24. Whitcomb DC, and Block GD. Association of acetaminophen hepatotoxicity with fasting and ethanol use. JAMA. 272: 1845-1850. 1994. [Medline] [CrossRef]

25. Rumack BH. Acetaminophen misconceptions. Hepatology. 40: 10-15. 2004. [Medline] [CrossRef]

26. Dahlin DC, Miwa GT, Lu AY, and Nelson SD. N-acetyl-pbenzoquinone imine: a cytochrome P-450-mediated oxidation product of acetaminophen. Proc Natl Acad Sci USA. 81: 1327-1331. 1984. [Medline] [CrossRef]

27. Miller KW, and Yang CS. Studies on the mechanisms of induction of $\mathrm{N}$-nitrosodimethylamine demethylase by fasting, acetone, and ethanol. Arch Biochem Biophys. 229: 483-491. 1984. [Medline] [CrossRef]

28. González-Jasso E, López T, Lucas D, Berthou F, Manno M, Ortega A, and Albores A. CYP2E1 regulation by benzene and other small organic chemicals in rat liver and peripheral lymphocytes. Toxicol Lett. 144: 55-67. 2003. [Medline] [CrossRef]

29. Pessayre D, Dolder A, Artigou JY, Wandscheer JC, Descatoire V, Degott C, and Benhamou JP. Effect of fasting on metabolite-mediated hepatotoxicity in the rat. Gastroenterology. 77: 264-271. 1979. [Medline]

30. Strubelt O, Dost-Kempf E, Siegers CP, Younes M, Völpel M, Preuss U, and Dreckmann JG. The influence of fasting on the susceptibility of mice to hepatotoxic injury. Toxicol Appl Pharmacol. 60: 66-77. 1981. [Medline] [CrossRef]

31. Kondo K, Yamada N, Suzuki Y, Toyoda K, Hashimoto T, Takahashi A, Kobayashi A, Shoda T, Kuno H, and Sugai S. Enhancement of acetaminophen-induced chronic hepatotoxicity in restricted fed rats: a nonclinical approach to acetaminophen-induced chronic hepatotoxicity in susceptible patients. J Toxicol Sci. 37: 911-929. 2012. [Medline] [CrossRef] 
32. Gonzalez FJ. The 2006 Bernard B. Brodie Award Lecture. Cyp2el. Drug Metab Dispos. 35: 1-8. 2007. [Medline] [CrossRef]

33. Brown BL, Allis JW, Simmons JE, and House DE. Fasting for less than $24 \mathrm{~h}$ induces cytochrome P450 2E1 and 2B1/2 activities in rats. Toxicol Lett. 81: 39-44. 1995. [Medline] [CrossRef]

34. Bruckner JV, Ramanathan R, Lee KM, and Muralidhara S. Mechanisms of circadian rhythmicity of carbon tetrachloride hepatotoxicity. J Pharmacol Exp Ther. 300: 273-281. 2002. [Medline] [CrossRef]

35. Rui L. Energy metabolism in the liver. Compr Physiol. 4: 177-197. 2014. [Medline] [CrossRef]

36. Mahoney LB, Denny CA, and Seyfried TN. Caloric restriction in $\mathrm{C} 57 \mathrm{BL} / 6 \mathrm{~J}$ mice mimics therapeutic fasting in humans. Lipids Health Dis. 5: 13. 2006. [Medline] [CrossRef]

37. Qin LQ, Wang Y, Xu JY, Kaneko T, Sato A, and Wang PY. One-day dietary restriction changes hepatic metabolism and potentiates the hepatotoxicity of carbon tetrachloride and chloroform in rats. Tohoku J Exp Med. 212: 379-387. 2007. [Medline] [CrossRef]

38. Sendelbach LE, White CA, Howell S, Gregus Z, and Klaassen CD. Effect of sulfhydryl-deficient diets on hepatic metallothionein, glutathione, and adenosine 3'-phosphate 5'-phosphosulfate (PAPS) levels in rats. Toxicol Appl Pharmacol. 102: 259-267. 1990. [Medline] [CrossRef]

39. Tateishi N, Higashi T, Naruse A, Nakashima K, and Shio- zaki H. Rat liver glutathione: possible role as a reservoir of cysteine. J Nutr. 107: 51-60. 1977. [Medline] [CrossRef]

40. Higashi T, Tateishi N, Naruse A, and Sakamoto Y. A novel physiological role of liver glutathione as a reservoir of Lcysteine. J Biochem. 82: 117-124. 1977. [Medline] [CrossRef]

41. Bélanger PM, Desgagné M, and Bruguerolle B. Temporal variations in microsomal lipid peroxidation and in glutathione concentration of rat liver. Drug Metab Dispos. 19: 241-244. 1991. [Medline]

42. Albrecht R, Pelissier MA, Atteba S, and Smaili M. Dietary restriction decreases thiobarbituric acid-reactive substances generation in the small intestine and in the liver of young rats. Toxicol Lett. 63: 91-96. 1992. [Medline] [CrossRef]

43. Xia E, Rao G, Van Remmen H, Heydari AR, and Richardson A. Activities of antioxidant enzymes in various tissues of male Fischer 344 rats are altered by food restriction. $\mathrm{J}$ Nutr. 125: 195-201. 1995. [Medline]

44. Mohammadi M, Ghaznavi R, Keyhanmanesh R, Sadeghipour HR, Naderi R, and Mohammadi H. Caloric restriction prevents lead-induced oxidative stress and inflammation in rat liver. Sci World J. 2014: 821524. 2014. [Medline] [CrossRef]

45. Stankovic M, Mladenovic D, Ninkovic M, Vucevic D, Tomasevic T, and Radosavljevic T. Effects of caloric restriction on oxidative stress parameters. Gen Physiol Biophys. 32: 277-283. 2013. [Medline] [CrossRef] 